\title{
Understanding the Participation, Perceptions, and Impacts of Engineering Faculty Learning Communities: A Mixed Method Approach
}

\author{
Prof. Ziyu Long, Colorado State University \\ Ziyu Long is an assistant professor in organizational communication at Colorado State University.
}

Mr. Sean Eddington, Purdue University

Jessica Pauly

Ms. Linda Hughes-Kirchubel, Purdue University

Linda Hughes-Kirchubel received her master's in organizational communication from Purdue University, where she works in the College of Health and Human Sciences. A former journalist, she has earned national recognition for her work. She is pursuing her Ph.D. at Purdue using mixed methods to study intersections among media, marginalized populations and disenfranchised grief. In addition, she has coauthored chapters in a Springer book series called "Risk and Resilience in Military and Veteran Families" and is an adjunct professor of communication studies at Ivy Tech Community College.

\section{Prof. Klod Kokini, Purdue University, West Lafayette}

Klod Kokini, Ph.D. is a Professor of Mechanical Engineering at Purdue University and the Associate Dean for Academic Affairs in the College of Engineering. He received his B.S.M.E. from Bogazici University in Istanbul, Turkey; his M.S.M.E. and Ph.D. degrees from Syracuse University in Syracuse, New York.

Professor Kokini's research activities include the study of failure mechanisms and design of high-temperature advanced materials such as functionally graded and composite ceramic thermal barrier coatings. He also works on interdisciplinary research related to the biomicromechanics of ECM-cell interactions.

He is an ASME Fellow (2002) and a Fellow of the American Institute for Medical and Biological Engineering (2008) as well as a member of the ASME Diversity and Inclusion Strategy Committee. He was on the Board of Directors of WEPAN / Women in Engineering ProActive Network between 2011-2014. He was a co-PI on Purdue's NSF ADVANCE grant for Institutional Transformation (2008-2013). He was the recipient of the Dreamer Award, Purdue University's highest award which recognizes contributions to diversity activities and named in honor of Martin Luther King, Jr. (2005). He was the first male recipient of the Violet Haas Award given by the Council on the Status of Women at Purdue in recognition of outstanding efforts on behalf of women (2007). In 2008, he received the ASME Johnson and Johnson Consumer Companies Medal, for his "unwavering commitment to diversity".

\section{Prof. Patrice Marie Buzzanell, Purdue University, West Lafayette}

Patrice M. Buzzanell is a Distinguished Professor in the Brian Lamb School of Communication and the School of Engineering Education (courtesy) at Purdue University. She is the Butler Chair and Director of the Susan Bulkeley Butler Center for Leadership Excellence. Editor of three books and author of over 160 journal articles and chapters, her research centers on the intersections of career, gender communication, leadership, and resilience. Fellow and past president of the International Communication Association, she has received numerous awards for her research, teaching/mentoring, and engagement. She is working on Purdue-ADVANCE initiatives for institutional change, the Transforming Lives Building Global Communities (TLBGC) team in Ghana through EPICS, and individual engineering ethical development and team ethical climate scales as well as everyday negotiations of ethics in design through NSF funding as Co-PI. [Email: buzzanel@purdue.edu] 


\title{
Understanding the Participation, Perceptions, and Impacts of Engineering Faculty Learning Communities: A Mixed Method Approach
}

\begin{abstract}
As important community assets for sustainable development of engineering education, faculty Learning Communities (FLCs) play an important role in facilitating faculty development and career transitions. Viewing FLCs as community-based programs with great diversity, the current research argues that engaging with new/junior engineering faculty as a learning community has important impacts to engineering education for students, institutions, and the communities that we work with and live in (Cox 2004). Specifically, guided by theories about communities of practice and socialization, we investigate the participation, outcomes, and perceptions of a New Faculty Learning Community (NFLC) program in the College of Engineering of a large Midwestern research university and discuss lessons learned from the design of these programs. The research followed a two-phase sequential mixed methods design that employed a survey and follow-up interviews. Survey results indicated that the most highly ranked benefits of NFLC included providing opportunities to connect with other new faculty, fostering a sense of community, and learning professional development strategies. Interviews further revealed NFLC offered a welcoming space for advice seeking, networking, informal mentoring, and served as a symbol of leadership support for faculty success. However, quantitative analyses indicated that proactive personality, rather than NFLC participation itself, was a statistically significant predictor of faculty members' feelings of identification, acculturation, involvement with their department/college, and their overall feelings of meaningfulness of and happiness in life, offering important insights for designing community-based educational initiatives to fostering proactive mindset and behaviors of faculty. The findings reinforce the positive impact of FLCs in faculty learning and pose suggestions for FLCs to encourage and foster proactive behaviors for the success and wellbeing of the community of engineering faculty.
\end{abstract}

Keywords: Faculty learning community, socialization, proactive behaviors, career success, mixed methods, engineering 


\section{Introduction}

Engineering faculty form a crucial community in engineering education as faculty members' goals and values, outreach and engagement, scholarly achievement, teaching success as well as their own wellbeing can shape the development of engineering as a discipline, the higher institutions that they work for, and their day-to-day interactions with students, organizations, and local communities both at home and abroad. The current research views engineering faculty as a highly diverse and internal university community and crucial assets that should be nurtured, developed, and fully utilized. It also assesses and explores connections between community-based learning programs for new/junior engineering faculty development and the shaping of engineering education in areas such as research, teaching, and community engagement success.

While faculty learning and socialization are essential to overall productivity and success of engineering education, engineering faculty as a community face many challenges in an era of tightening budgets, data-driven decision-making, tougher demands on faculty productivity, and looming changes to faculty tenure processes in academia. New and junior faculty are tasked with being more productive, more innovative, and savvier than before with their research, publications, grants, teaching and engagement (service) as traditional pathways for faculty tenure and promotion are more demanding than ever. As a result, universities offering orientation programs like faculty learning communities (FLCs) have provided one programmatic avenue to mitigate these external challenges while concurrently socializing newcomers.

FLCs play an important role in facilitating faculty development and growth, as well as enhancing a welcoming climate and sense of wellbeing. Thus, these programs have potential to improve faculty retention and success, and help transform higher education institutions into learning organizations (for a review, see Cox, 2004). Additionally, FLC programming serves as an important way to cultivate relationships through which community-based research collaborations and teaching opportunities emerge (Hubball \& Albon, 2007; Smith et al., 2008). Broadly, FLCs "address the teaching, learning, and developmental needs of an important cohort of faculty" (Cox, 2003, p. 163). Similar to student learning communities that are present on college campuses, FLCs are designed as a multidisciplinary approach to increase outcomes related to "faculty retention, faster intellectual development, greater civic contributions, and more active, learner-centered....approaches to teaching" (Cox, 2003, p. 162). FLCs contribute to a newcomer's success at the university, and can be one way to manage the changing landscape of academia. As noted before, such programs to engage faculty community can have important impact for the wellbeing of the faculty as well as the engineering education as a whole. Many focus largely or exclusively on teaching and learning topics (Cox, 2004) and are crossdisciplinary, yet FLC programs in the engineering discipline remain relatively new. As such, there is a growing need to establish empirical and theoretical understandings of these communities and their impacts on faculty in order to better inform best practices. 
The current research takes a mixed methods approach to understand the participation, perceptions and outcomes of a New Faculty Learning Community (NFLC) program in the College of Engineering at a large Midwestern research university in the United States. Drawing from existing research on FLCs and theories in socialization and community practice, this study contributes to the existing knowledge of FLCs by (a) investigating the FLC experience from the faculty participants' perspectives and offering both quantitative and qualitative base-level understandings of engineering faculty's participation and perceptions of NFLC; (b) situating understandings of FLCs in the larger theoretical framework of newcomer socialization and career learning/development, on which to build theoretical models to design better faculty learning experiences; and (c) highlighting the salient role proactive behaviors/mentality in faculty learning and socialization to improve FLCs in ways that promote proactivity and inclusivity.

The study also responds to the call of Community Engagement in Engineering Education Division in a few important ways. First, the project focuses on faculty community, rather than external communities such as companies or local residential communities. The definition of community we adopted is not just in a physical location, but in an organizational location, in "the cooperation in labor, order and management," (Tönnies, 2000, p. 43). This is important in our consideration of community of engagement, as we go beyond physical boundaries, such as those between university and its wider locale, to cognitive boundaries, such as those within and among university colleges and departments. It is with this in mind that we define engagement and engaged communities. Second, it expands the definitions and model of community engagement by highlighting how engineering faculty, particularly those who are new, can be an important community itself that needs to be more fully engaged for better community engagement in engineering education (which includes building community partnerships, innovating communitybased efforts, and establishing collaborative and learning models with engineering students, faculty, institutions, communities, and other stakeholders). Third, we provide lessons learned in implementing and sustaining a community-based educational initiative, in this case, the NFLC program, and teased out the challenges and opportunities that emerged in this initiative given the diversity of faculty members in terms of their backgrounds and experiences. These lessons have transferrable values to inform other community-based learning and collaboration design.

In what follows, we first provide a brief background of faculty learning communities, then a review of literature on relevant constructs of the theoretical framework from which we investigate faculty's participation, perceptions, and perceived outcomes of the NFLC. These constructs include newcomer socialization with a focus on organizational identification, acculturation, and involvement, as well as the role proactive personality plays in career transition and continued development. Next, we discuss our mixed methods research design and present the quantitative and qualitative findings based on survey and interview data respectively. We conclude by offering theoretical and practical implications to researchers, faculty, and university leaders interested in cultivating communities for faculty success and wellbeing.

\section{Literature Review}

Faculty Learning Community (FLC) 
With early developments in the 1970 s, the implementation of the faculty learning community became widespread in the mid-1990s (Cox, 1999). Using Miami University as an example, Cox points to the decision that took place in the 1990s to rename the faculty development program to a faculty learning community. This new faculty learning community focused on collaborative work over the course of one year's time, aimed at enhancing teaching and learning while also building community (Cox, 2004). What differentiated the faculty learning community from the faculty development program was the continuous, year-long process of learning, reflection, and support by colleagues.

Another important difference is that faculty learning community emphasized on relationship development and community building among faculty. As noted by prior research on socialization, successful relationships cultivated through organizational connections further embed and empower individuals to participate, identify, and engage more deeply with their organization (Kramer \& Miller, 2014, see also Illiesa, Dimotakisc \& Spitzmullera, 2013). FLCs designed specifically for new faculty, as in the case of this study, provide coaching and leadership opportunities for individuals who are already experiencing organizational change and transition. It is therefore conceivable to expect that participation in NFLCs may have an impact on the faculty member that, in turn, has an impact on the wider organization.

In 2004, New Directions for Teaching and Learning published a comprehensive volume focusing specifically on faculty learning communities (see volume 97). Similarly, within organizational studies, communities of practice $(\mathrm{CoP})$ are another way of conceptualizing the importance of FLCs. Wenger, McDermott, and Snyder (2002) define CoPs as "groups of people who share a concern, a set of problems, or a passion about a topic, and who deepen their knowledge and expertise in this area by interacting on an ongoing basis" (p. 4). Rooted within Lave and Wenger's situated learning theory, CoPs exist "as the context in which an individual develops the practices (including values, norms and relationships) and identities appropriate to that community" (Handley et al., 2006, p. 642).

Further exploring CoPs, knowledge, understanding, meaning-making, and other forms of organizational learning exist within regular meetings that occur (Easterby-Smith, Crossnan, Nicolini, 2000). Related to FLCs, membership within specialized knowledge communities -- like CoPs -- foster socialization, learning, and understanding related to specific group goals, but existing literature does not adequately address short-term groups, like FLC membership. (Lindkvist, 2005). Additionally, Hydle, Kvålshaugen, and Joachim Breunig (2014) challenge the existing CoP framework by deconstructing CoPs into two separate frameworks: communites of task (examples include working groups or research teams), and communities of learning (examples include mentoring spaces in which knowledge and created and shared). CoPs are intriguing considering the function of the broad function of FLCs as a site for organizational learning and transition. Returning to FLCs, since 2004, the topic has received little attention. Past scholarship has examined cross-disciplinary faculty communities (Hubball \& Albon, 2007) and discipline-specific faculty learning communities (Addis et al., 2013; Tovar, Jukier, Ferris, \& Cardoso, 2015) yet additional studies are necessary in order to confirm the effectiveness of and 
motivations behind faculty learning communities (Glowacki-dudka \& Brown, 2007; Hubball \& Albon, 2007).

In order to understand the design, participation, and outcomes of new faculty learning communities, we asked the following overarching research questions to guide our investigation:

RQ-1: How do faculty describe their participation (or lack of participation) in NFLC?

RQ-2: What roles do faculty report that the NFLC play in new faculty development?

Organizational Socialization

Organizational socialization is the ongoing behavioral and cognitive processes in which an individual becomes part of the organization's pattern of activities (Anderson, Riddle, \& Martin 1999; Jablin \& Krone, 1987). The socialization processes involve both parties. On one hand, organizations can socialize individuals through institutionalized socialization tactics such as training or mentoring (Long, Buzzanell, Anderson, Batra, Kokini, \& Wilson, 2014). On the other hand, individuals can participate in individual socialization such as engaging in various information-seeking tactics (Kramer \& Miller, 2014). Effective socialization can lead to outcomes such as organizational identification, acculturation, recognition, and involvement.

People tend to classify and identify themselves into various social categories that are constituted on both individual and group levels (Ashforth \& Mael, 1989; Hogg \& Terry, 2000; Kramer \& Miller, 2014). Social identity and organizational identification are both a process and a product of the dynamic relationship between organization and individual (Cheney, Christensen, \& Dailey, 2014). While group members might identify with multiple intersections of identity (on both micro and macro levels), "the social identity approach enables us to formulate further predictors about work conditions that encourage feelings of identification" (Ellemers et al, 2004, p. 463). Training programs, organized lunches, and relationships contribute to an overall commitment toward an organization (Postmes, Tanis, \& de Wit, 2001). Possessing an affinity toward one's own organization has been shown to be a positive indicator of career success (Ellemers et al, 2004). Ashforth and Mael (1989) further define social identification as "the perception of oneness with a belongingness to some human aggregate" (p. 21).

Additionally, success within an organization for newcomers is predicated on one's ability to be integrated into the organization (learning departmental norms, behaviors, and even political landscapes and becoming a part of the organization) present within the workplace, a process that can occur concurrently with organizational programming as a means to socialize newcomers to their new setting. Organizational integration can manifest in aspects such as levels of organizational acculturation, familiarity and recognitions of other members, and involvement of the organizational life (Myers \& Oetzel, 2003). Organizational acculturation can be indicated by a development of a shared understanding by organizational members regarding organizational goals, values, and general structures and procedures. When members are acculturated, they usually have accepted the general goals and values of the organization, and are willing to integrate into the culture. Familiarity with other individuals from the organization (i.e., get to know the colleagues and establish relationships with members) can foster relationships (in both 
micro and macro-levels) bond individuals to their organizations, and become a way to increase perceptions of self-efficacy and commitment toward the organization (Cheney et al, 2014). Recognition from others (i.e., perceiving one's value to the organization and feeling recognized) can also link to job satisfaction, commitment, and a sense of identification (Myers \& Oetzel, 2003). Furthermore, effective socialization can lead to higher involvement, which encompasses many aspects of being a part of an organization. Research suggested early involvement with the organization could translate to new comers' higher levels of productivity and cause new comer to feel more acceptance and less role conflict (Myers \& Oetzel, 2003).

Based on the above discussion of organizational socialization, we propose the following hypotheses:

H-1a: Faculty who participate in NFLC are more likely to identify with their department/college.

H-1b: Faculty who participate in NFLC are more likely to become integrated to their department/college.

\section{Proactive Personality}

Organizational newcomers such as new faculty members can experience a "sink or swim" phenomenon during the learning process. Those who are able to "swim" oftentimes are able to take advantage of organizational offerings to help mitigate and provide clarity for various points of uncertainty within the organization. Meanings are negotiated as "newcomers experiences uncertainty about many things - the nature of their jobs and how to perform them, the norms and culture of the organization, and their relationships to coworkers and supervisors" (Kramer \& Miller, 2014, p. 528). One of the important ways that newcomers manage uncertainty in the organization is through seeking information to decrease their uncertainty; in doing so, they engage in proactive behaviors (Bateman \& Crant, 1993; Crant, 1995; Kramer \& Miller, 2014). This strategy, what Lankau and Scandura (2007) describe as rooted in development and information seeking processes, enables individuals to thrive in their new uncertain environments. Their ability to be involved in learning opportunities, training programs, and other forms of development programs increase individual's perceived sense of efficacy, and perceived sense of use for these programs.

In managing uncertain environments, seeking new information and looking for solutions to emerging issues are two ways that proactivity is manifested. Crant (1995) defines proactive behaviors as "the extent to which [individuals] take action to influence their environment." Proactive behaviors are influencing one's environment in that they are managing and alleviating individual uncertainty with regard to the newcomer experience. Individuals possessing proactive personalities are highly active and engaged in the organizational socialization process, they are go-getters, and are persistent in mitigating uncertainty. Bateman and Crant (1993) assert that newcomers can intentionally change their circumstances and environments through proactivity. As such, proactive behavior has also been shown to positively influence job performance (Bateman \& Crant, 1993; Crant, 1995). As proactivity increases, so does involvement in work activities and cultivation of relationships. 
Proactive personality research is also ripe in the ways in which proactive behaviors cultivate and influence relationship-building. Relationships become a benchmark for job satisfaction, as "proactive employees actively manage relationships with their supervisors and ultimately experience greater job satisfaction than do their less proactive coworkers" ( $\mathrm{Li}$, et al., 2010, p. 401). Relationships become a way that individuals thrive in an organization, and proactive personalities play into relational cultivation. Thompson (2005) notes, "proactive employees do not operate in a social vacuum. Rather, they must leverage the support of others in their support of others in their pursuit of self-directed objectives" (p. 1012). Relationships become an organizational strategy for success. For example, job training and "hidden" expectations can emerge through informal relationships.

Where specific job-related tasks are described and trained through direct supervisors, $\mathrm{Li}$ et al. (2011) describes, "more specific task behaviors and group role expectations [are shared] from experienced coworkers in similar jobs" (p. 3). Relational networks become important for organizational success, and oftentimes, the social currency created in these connections become important ways for newcomers to prevent or navigate organizational pitfalls (Li et al, 2014). The result of these relationships includes an increased feeling of self-efficacy and agency in the organization. Individuals are able to feel confidence exerting influence and control, "which in turn contributes to further advancement of proactive personality over time" (Li et al., 2014, p. 958). Understanding the role of proactive personalities in organizational involvement, we propose the following research question and hypotheses:

RQ-3: How does proactive personality relate to faculty's involvement and perceived outcome of NFLC and verse versa?

H-2a: Faculty with stronger proactive personality are more likely to participate in NFLC $\mathrm{H}-2 \mathrm{~b}$ : Faculty with stronger proactive personality are more likely to identify with their department/college.

$\mathrm{H}-2 \mathrm{c}$ : Faculty with stronger proactive personality are more likely to be integrated to their department/college.

We summarize our list of research questions and hypotheses as follows:

RQ-1: How do faculty describe their participation (or lack of participation) in NFLC?

RQ-2: What roles do faculty report that the NFLC play in new faculty development?

H-1a: Faculty who participate in NFLC are more likely to identify with their department/college.

H-1b: Faculty who participate in NFLC are more likely to be integrated to their department/college.

RQ-3: How does proactive personality relate to faculty's involvement and perceived outcome of NFLC?

H-2a: Faculty with stronger proactive personality are more likely to participate in NFLC $\mathrm{H}-2 \mathrm{~b}$ : Faculty with stronger proactive personality are more likely to identify with their department/college.

H-2c: Faculty with stronger proactive personality are more likely to be integrated to their department/college. 


\section{Methods}

Participants

Faculty from the College of Engineering at a large Midwestern research university were invited to participate in this mixed method study on NFLC if they had joined the College of Engineering (CoE) within the past ten years (2004-2015), and were a current faculty member of the college. To provide a brief overview of the NFLC, it is a program established by the CoE in 2010 as a response to faculty interests in orientation and learning opportunities. The NFLC holds three sessions per semester and spend 90 minutes together - often over the lunch period discussing topics such as research, relationship negotiation with senior faculty, and promotion and tenure, to name a few. The aims of the NFLC are twofold: (1) to share information with newly hired $\mathrm{CoE}$ faculty, and (2) to build a sense of community within the college. Experience with the NFLC was not required in order to participate in our study. We recruited participants for the two phases of the study -- online survey and in depth interview -- separately.

We first recruited eligible faculty to participate in an online survey exploring their socialization and acculturation into the college organizational setting (for details of the survey, see next section). After receiving approval from our university's Institutional Review Board, the research team obtained contact information (email address) of the faculty members from the College of Engineering's website. Invitation emails with a link to the online survey were sent out to faculty members' email accounts listed on the website to solicit participation. Two rounds of reminder emails were sent after the initial recruitment message.

Forty-nine faculty members completed the online survey $(n=49)$. Within this sample, there were 16 women (33\%), and 33 men (67\%). Three-quarters ( $n=36,73 \%)$ were between the ages of 25 and 45. Additionally, the survey participants represented a multiethnic swath from the college of engineering; of the self-reported data, 21 of the participants (43\%) identified as white, Caucasian, or Anglo-Saxon. Three of the participants identified as Asian (6\%), and two participants identified as Hispanic or Latino (4\%). Also of note, 23 of the survey participants did not provide information related to their ethnicity (47\%). The participants also represented a variety of ranks within the College of Engineering faculties. Of the participants who reported their rank $(\mathrm{n}=48), 25$ of them identified as an assistant professor $(52 \%)$, with 16 as associate professor $(33 \%)$, six as full professor $(13 \%)$, and one as a professor of practice $(2 \%)$.

Participants for the interview study were recruited through two methods. First, after the faculty participants completed and submitted the online survey, they were asked if they are interested to participate in an interview about their NFLC experience in the next webpage. They were notified that this is a separate invitation, completely voluntary, and their survey responses would not be linked to their identity. If participants agreed to take part in the interview, they were then prompted to leave their contact information for researchers to schedule interviews at a time and place of their convenience. In addition, researchers sent invitation emails to the email listserv created during the survey recruitment to solicit participation. They were notified that participation was completely voluntary and all responses were confidential. Participants could skip any questions they did not want to respond to in the interview. 
Fifteen members of the College of Engineering $(n=15)$ participated in in-depth interviews. Within this sample, there were five women (33\%), and ten men (67\%). The sample was also ethnically diverse with two of the participants identifying as Asian (13\%), one participants (7\%) identifying as Hispanic, one participant identifying as Iranian (7\%), and 11 of the participants identifying as White (73\%). Finally, the sample also identified faculty rank, and 10 of the participants $(67 \%)$ holding the rank of assistant professor, two participants (13\%) identified as associate professors of practice, two participants (13\%) identified as full professors of practice, and one participant (7\%) identified as a full professor.

Data Collection and Analysis

The research followed a two-phase sequential mixed method design (Creswell \& Plano Clark, 2007). A mixed methods design was adopted in this project because of its ability to extend the breadth and range of inquiry by using different methods, to clarify results from one method with the results from the other method(s), and to seek elaboration enhancement, convergence, and corroboration of results of different methods (Greene, Caracelli, \& Graham, 1989). We elaborate on our two-phase design as follows.

In the first phase, the research team designed a survey based on existing scales and practical insights from experienced NFLC facilitators and university administrators. The survey was conducted with faculty members ( $n=49$, with 29 participated in the NFLC) who were hired since 2004 with special attention to faculty who started after 2011 (the initiation of the NFLC program). The survey captured engineering faculty members' participation in NFLC program, performances in research and teaching, their socialization experience--level of identification with the university and department (Mael \& Ashforth, 1992) and organizational assimilation (Myers, \& Oetzel, 2003), proactive personality (Bateman \& Crant, 1993), and sense of meaningfulness and happiness (Baumeister \& Vohs, 2002). Organizational identification is measured by Mael and Ashforth's (1992) 5-item scale, ranging from 1 (strongly disagree) to 5 (strongly agree) (OI1 to OI-5; $(\alpha=$.914) Organizational integration is measured by a shortened version of Myers and Oetzel's (2003) Organizational Assimilation Index (OAI), ranging from 1 (strongly disagree) to 5 (strongly agree). The scale includes three items for familiarity with supervisors $(\alpha=.835)$, four items for acculturation $(\alpha=.864)$, four items for recognition $(\alpha=.946)$, three items for involvement $(\alpha=657)$. Proactive personality is measured by a shortened version of Bateman and Crant's (1993) Proactive Personality Scale, with 10 items ranging from 1 (strongly disagree) to 7 (strongly agree) $(\alpha=.784)$. Singles items were used to measure meaningfulness and happiness, respectively.

Descriptive analyses were run to provide a baseline data of the participation of NFLC, perceived benefits of NFLC, and faculty development outcomes in research, teaching, and mentoring graduate students. To address RQs and test the hypotheses, ANOVA, Chi-square, and Regression analyses were run to explore the relationship between participation in NFLC, perceived outcomes, proactive personality, organizational identification, organizational assimilation, and level of happiness and wellbeing. 
In the second phase, in-depth qualitative interviews $(n=15)$ were conducted with faculty members who had participated in the NFLC. The interviews were semi-structured to allow the natural flow of conversation and opportunities to ask follow-up questions. These interviews lasted from 30 to 75 minutes, generating a total of 213 pages of transcripts. After the interviews were transcribed and checked for accuracy, the audio recordings were permanently deleted. Pseudonyms were used to protect participants' identity. After reading and rereading the transcripts, thematic analyses were conducted first separately by researchers. Repetition of terms, recurrence of ideas, and forcefulness were leveraged as criteria to identify themes (Owen, 1984). After initial round of analysis, the researchers engaged in multiple rounds of discussions of their analysis to surface salient themes, nuances and relationships of different sub-themes, unexpected findings, negative cases, interconnections of the qualitative (based on interviews) and quantitative (based on online survey) findings and so on. Notes were taken throughout the research meetings and circulated among the entire research team. Through iterative data analysis, the research team reached consensus of the thematic findings and continued their analysis through collaborative writing interactions of the paper (e.g., commenting, editing, asking questions to broaden/deepen the findings).

\section{Quantitative findings}

Of the faculty surveyed ( $n=49), 29$ faculty stated that they participated in the NFLC programming, conversely, 20 of the participants stated that they did not participate. Regarding RQ-1 about reasons faculty reported about their attendance of NFLC, 12 out of 20 nonparticipant faculty noted that they had not heard of the NFLC; however, the other eight participants stated that they had heard of the NFLC or were invited but could not attend due to schedule conflicts, teaching commitments, overall busy-ness, or the programming did not meet their specific needs. For example, one faculty member noted, "I've been a faculty member for 20 years at other institutions and have not prioritized this activity since joining Purdue. In addition, many of the topics seem to be geared toward young/new assistant professors." Others noted an uncertainty as to whether they had been specifically invited to attend the NFLC. To understand gender differences in faculty's participation rate of NFLC, a Chi-square test was conducted crossing variables gender (male, female, and other) and entrepreneurial participation (yes, no). Results suggested there were no significant difference between male and female in their participation of NFLC $\left(\mathrm{X}^{2}(2)=.20, p=.90, \Phi=.07\right)$.

Regarding RQ-2 about faculty's perceived role of NFLC, descriptive results provided some baseline data in understanding faculty's general understandings and perceived outcomes of NFLC. In general, faculty members who have participated in the NFLC $(n=29)$ were satisfied (5point scale) with their experiences $(\mathrm{M}=4.03)$. The most highly ranked perceived outcomes of NFLC included providing opportunities to connect with other new faculty $(M=4.24)$, learning professional development strategies $(M=4.10)$, fostering a sense of community $(M=3.97)$, and offering useful information for achieving success as a faculty member $(\mathrm{M}=3.90)$.

Regarding the first set of hypotheses about NFLC participation's impact on faculty member's socialization to the college, statistical results indicated faculty's participation in NFLC does not significantly influence their identification with or assimilation to the college. In 
to test H-1a that predicted faculty who participate in NFLC are more likely to identify with the organization, a one-way ANOVA was conducted to compare effect of participation of NFLC on faculty's organizational identification. The result was not significant, $\mathrm{F}(1,47)=.112, p=.74$, meaning that participation in NFLC does not significantly influence organizational identification. To test $\mathrm{H}-1 \mathrm{~b}$ that predicted faculty who participate in NFLC are more likely to be integrated to their current work position, a set of one-way ANOVA were conducted to compare effect of participation of NFLC on familiarity with supervisors, $\mathrm{F}(1,47)=.89, p=.35$; acculturation $\mathrm{F}(1$, $47)=.001, p=.98$; recognition $\mathrm{F}(1,47)=.015, p=.90$; and involvement $\mathrm{F}(1,47)=.127, p=.72$. Therefore, $\mathrm{H}-1 \mathrm{~b}$ is not supported.

Regarding the second set of hypotheses about faculty's proactive personality level and their NFLC experience, statistical analyses suggested that proactive personality, rather than participation in NFLC, was a statistically significant predictor of faculty member's feeling of identification, acculturation, involvement with their department, and the overall feelings of meaningfulness and happiness of life. Interestingly, proactive personality does not predict participation in FLC $(\mathrm{F}(1,47)=.17, \mathrm{p}=.68)$. Therefore $\mathrm{H}-2 \mathrm{a}$ is not supported. To test Hypothesis$2 \mathrm{~b}$ : Faculty with stronger proactive personality are more likely to identify with the organization. A simple linear regression was calculated to predict organizational identification based on proactive personality. A significant regression equation was found, $\mathrm{F}(1,47)=11.88, p=.001$, with an $\mathrm{R}^{2}$ of .20. Participants' level of proactive personality is positively related to their perceived sense of identification with the organization $(\beta=.45, p=.001)$. Therefore, $\mathrm{H}-2 \mathrm{~b}$ is supported. To test $\mathrm{H}-2 \mathrm{c}$, faculty with stronger proactive personality are more likely to be integrated to their current work positions, a series of linear regressions were calculated to predict different dimensions of organizational integration based on proactive personality. Although proactive personality does not predict familiarity with supervisors $(\mathrm{F}(1,47)=2.48, p=.12)$ or recognition $(\mathrm{F}(1,47)=.91, p=.35)$, it predicts faculty participants' perceived level of acculturation to their department and a sense of involvement. Regarding acculturation, linear regression was calculated to predict acculturation based on proactive personality. A significant regression equation was found, $\mathrm{F}(1,47)=10.08, p=.003$, with an $\mathrm{R}^{2}$ of .18. Participants' level of proactive personality is positively related to their perceived level of acculturation with the organization $(\beta=.42, p=.003)$. Regarding involvement, a simple linear regression was calculated to predict involvement based on proactive personality. A significant regression equation was found, $\mathrm{F}(1$, $47)=5.50, p=.02$, with an $\mathrm{R}^{2}$ of .11. Participants' level of proactive personality is positively related to their perceived level of involvement with the organization $(\beta=.32 p=.02)$.

Participants with a higher level of proactive personality also tend to experience a higher level of happiness and perceive life to be more meaningful compared to those with low level of proactive personality. Regressing level of happiness against proactive personality, a significant regression equation was found, $\mathrm{F}(1,47)=7.62, p=.008$, with an $\mathrm{R}^{2}$ of .14. This result indicates that participants' level of proactive personality is positively related to their level of happiness ( $\beta$ $=.37 p=.01)$. Regressing level of meaningfulness against proactive personality, the result was significant, $\mathrm{F}(1,47)=15.91, p=.00$, with an $\mathrm{R}^{2}$ of .25 . Participants' level of proactive personality is positively related to their level of meaningfulness $(\beta=.50 p=.00)$. In other words, 
individuals who have a proactive personality tend to experience a higher level of happiness and see their life as more meaningful compared to those who are less proactive.

\section{Qualitative findings}

Echoing the quantitative survey data, thematic analysis suggested that NFLC served a great platform for learning and networking with colleagues from across campus. In sharing their socialization experience, several faculty discussed their proactive approach to seek information, building mentoring and collaboration, and integrating into their local community. Interestingly, faculty framed NFLC as a context to learn about such proactive mindsets and strategies, and NFLC program itself showcased leadership support for faculty development which in turn encouraged faculty to engage in proactive behaviors to achieve career success and personal wellbeing. We discuss these findings in further details following the order of our research questions.

The qualitative findings from the interviews compliment survey results regarding RQ-1 about attractions/barriers for FLC participation. Three motivating factors emerged-learning something relevant and new, networking with faculty outside of the department, and gaining access to informal mentoring from senior faculty. Faculty indicated they benefitted from the information learned in the topics covered and the ability to ask questions of senior faculty. Roxanne, an assistant professor, said: "I think those luncheons were, in general, positive" because discussions centered around "topics that were relevant like research publication, getting funding, how to interact with senior faculty." She added that the meetings provided a place where new faculty could get questions answered, making NFLC "even more useful."

Those interviewed said they also prized the NFLC for the access to interactions among new and senior faculty of different College of Engineering departments. These networking opportunities built new relationships that may never have otherwise been formed. According to Max, an assistant professor: "There were connections made. I visited one of the faculty labs in bio-medical engineering based on similar interests that would not have come out of other avenues, I don't think." Interactions with other new faculty helped dissipate a sense of being alone in a new situation; Paul, an assistant professor, noted that participation in NFLC was "helpful to see that there's other people who also feel like they don't know what they're doing when they first get here." Most interviewees also said they valued the access provided to senior faculty members. "Participation made senior faculty more accessible," Max said. "My sense, I felt like it was easier to approach some of these more senior people or people that I might not have run across and allow us to kind of build that network." According to our participants, of particular use for new faculty were the insights of senior faculty in navigating many of the obstacles that could be encountered along the way. "It's helpful to sometimes be reminded of here's how you need to approach things," said Gabriel, an assistant professor who had only recently transitioned from the role of graduate student to faculty member.

To answer RQ-2 about NFLC's role in faculty development, the majority of faculty members perceived the outcomes of NFLC as positive: new and enhanced relationships with 
colleagues, a deeper understanding of the university and departmental structures and systems, and encouragement and support from the College.

Faculty members often mentioned the opportunity to build relationships with other colleagues as an ideal aspect of the NFLC. Meeting new faculty members opens opportunities to collaborate on teaching, research, and/or service. Some participants mentioned concerns regarding the process of connecting with others, yet thanks to the NFLC environment, they had a means of interacting and connecting based on shared interests and issues. One participant, Paul, a professor of engineering practice mentioned, "it helped accelerate some of the relationships" in his personal and professional life.

Beyond offering opportunities to network and build relationships, the NFLC was also perceived as a helpful resource, revealing the ins and outs of the university and departmental systems and processes. Concerns such as unwritten rules, learning differences between departments, and who to turn to or where to go with issues regarding travel, funding for teaching assistants, and supplies, were often addressed through the NFLC both reducing uncertainty and providing direction. Additionally, many participants referred to the NFLC being helpful because of the ability to talk through common problems sometimes leading to new perceptions or understandings. Betty, an assistant professor in mechanical engineering, shared her concerns regarding which graduate students to work with as a new faculty member: "I think every person we talked with has different opinions on how you pick a good student. The more feedback we can get, that did help. Also, I think we went through some scenarios like what if you pick the wrong student? How do you document the evidence, and eventually let them go. Things like that I don't think I would have known too much how to handle." By opening up with each other in this way, faculty members were not only able to develop personally and professionally, but also grow in community together. A few faculty also noted that they have established research collaborations through sharing experiences and resources. One participant explained: "The biggest (benefit) is that it (NFLC) helped me build these research relationships. We have a couple of grants funded because of this."

To answer RQ-3 regarding to proactive personality, many participants in the FLC appeared to engage in proactive behaviors and had a proactive mindset when it came to career development. Many framed NFLC as an important space to learn about how to be proactive to achieve their desired career/life goals. Max, an assistant professor in engineering education, said what he liked most about the NFLC was that it offered a "safe space" for him to be proactive in seeking advice and information — ask questions to senior faculty members and receive feedback from others who might also be experiencing the same things. These feelings were not Patricia, an assistant professor in Biomedical Engineering, explained the most memorable message she received from participating in the NFLC as: "The senior faculty interactions ... To be proactive and to reach out to the more senior faculty here ... if you want to meet somebody, go out and ask them to lunch. I took that to heart and I worked on meeting everybody in my department that I could, this last semester, to meet them for lunch or just a quick chat." After learning about these proactive strategies for networking, Patricia felt a sense of empowerment in making relationships happen instead of expecting them to develop on their own. Similarly, 
Baxter, an assistant professor in Materials Engineering/Environmental and Ecological Engineering had similar sentiments: "I'd have to say that yes, [the NFLC] has made a difference ... it pushed me towards investing time in making connections within my Baxter went on to reiterate that the NFLC taught and encouraged him to get out of his office and make connections - he felt compelled.

Qualitative findings also suggested faculty members experienced increased confidence and self-efficacy as a result of their participation in the NFLC, which in turn bolstered personal agency to be proactive. For instance, after being asked about networking opportunities through the NFLC, Max, an assistant professor in Engineering Education, admitted the NFCL "gave me confidence moving forward outside of the learning community to pursue faculty that I'm interested in their work or wanted to collaborate with." Max recognized the NFLC provided a solid foundation of information and connections upon which he felt capable of pursuing and building quality relationships with colleagues. An associate professor of Electrical and Computer Engineering, Karl shared that he, too, felt more proactive in taking risks with his teaching style after participating in the NFLC: "Seeing that the rest of Purdue is supportive of new methods of teaching probably made me feel confident to take some risks. It is a risk. I'm taking some risks." In the same vein, Betty summed up her positive perceptions of NFLC concisely when she stated the NFLC helped "jump start the new faculty's career," setting a good beginning for her to keep the momentum going and proactively develop herself as a researcher and a teacher. Terrance also commented on the jump start effect of NFLC, "the new community does a nice job of introducing you, but then once the introductions have been made, it's really an individual effort to strengthen those connections."

Beyond an increase in self-confidence, a few participants expressed increased confidence and identification with the university administration. For example, after being asked if the NFLC contributes to his personal and/or professional life, Jerry, an associate professor of practice responded, "Yeah. It also gave me confidence in all of our various deans and administrators around here." He continued to explain this confidence came through the organizer's empathy "towards the new faculty. They already iterated that their desire was for the success of all new faculty." Similarly, Karl, an assistant professor in Electrical and Computer Engineering noted the good intentions of the program development when he stated it "seemed like people who were genuinely trying to affect positive change." In this way, the encouraging and inspiring nature of the NFLC fostered proactivity for new faculty to develop to their fullest.

\section{Discussion}

As seen above, FLCs can play an important role in facilitating faculty development and growth and enhancing a welcoming climate and wellbeing. Our mixed methods research of the participation, outcomes, and perceptions of the NFLC program in a large Midwestern research university expands our knowledge of FLCs and their impacts on faculty learning and development.

Taking the quantitative and qualitative findings together, we found a general recognition and endorsement from faculty members of the intentions and commitment to faculty success 
behind the design of the NFLC program. During interviews, many faculty noted that the mere presence of our ongoing research suggested that the leaders within the college cared about their NFLC and faculty experiences in general. Furthering this point, both survey and interview data suggested the majority of faculty members perceived the NFLC as a positive experience for its ability to serve as "career jumpstarter"--providing opportunities to forge new relationships, building a supportive community, receiving mentorship from senior faculty, and gaining a deeper understanding of institutional policy and functioning. Not only did interactions at the NFLC events generate positive career outcomes (e.g., connections to departmental and college-wide peer networks, research connections, informal mentoring relationships, and providing a space through which new faculty could talk openly about their experiences), they also communicated the ethics of career and committed support for faculty success on behalf of the institution to the recently joined faculty, which could foster faculty proactivity for continued career learning and development.

However, concerns regarding to the sustainability and long-term career benefits of the NFLC emerged. Particularly, quantitative findings suggested that NFLC participation did not correlate with faculty success outcomes such as grants received, papers published, teaching excellence, or graduate student mentoring. Qualitative findings also suggested that it can be a challenge, but also an immense opportunity, to cultivate and sustain the learning communities after year-one. Faculty members acknowledged, and we agree, that the NFLC can generate longterm career benefit such as continued organizational socialization, professional skill acquisition (e.g., lab management, administration), grant/research collaboration, and (peer) mentoring relationships that go beyond the boundaries of formal cohort-based learning community interactions (e.g., NFLC is designed for first-year tenure track assistant professors). We need to think about how to create organic communities from a long term perspective and, ultimately, sustain the positive effects for faculty learning and institutional wellbeing and transformation.

Our findings revealed proactive personality as an important indicator for newcomers' sense of identification and integration into the organization. Faculty members with high levels of proactivity and involvement within their college are able to use FLC programming as the incubator for their own careers. Proactive mindset and behaviors do not operate in isolation as the sole factor of career success, but contribute to and expedite the socialization and integration process. These insights posit interesting questions regarding to the design of FLC programs: How can FLC programs better engage faculty who have a low level of proactive orientation? Given research on the positive correlation of proactive orientation and career success, how can FLC programs better foster proactive mindset of new faculty and encourage proactive behaviors? What unique benefits can FLC offer to those who are already actively forging connections and seeking information? What can be done to build self-sustaining FLCs that capitalize on the proactive personality of faculty?

\section{Practical Implications}

Our research also generated useful practical insights for the design and execution of FLC programs, which inform other community-based learning and collaboration design. To begin, we learned from our participants that timing can be an issue for NFLC attendance. It is important for 
faculty to be able to integrate NFLC participation to their working day (e.g., lunch or the late afternoon) and that NFLC activities take place on a rotating weekday (e.g., rotate on Monday and Tuesday).

Selecting relevant and specific topics is also highly important to attract NFLC participation. Faculty participants acknowledged the difficulty to meet all learning needs of a diverse body of new faculty and found the topics of NFLC about expectations and strategies of research, teaching, writing, and work-life issues useful. However, a couple of faculty suggested a stronger focus on research/teaching improvement and collaboration among faculty so that faculty can interact with each other on a deeper level to build sustaining learning communities. We encourage designers of NFLCs to reflect on how NFLC distinguish from other socialization/orientation programs and how to build and harvest the vast potential of forming sustaining communities on faculty learning.

In terms of the form of NFLC, the responses from faculty participants expressed a preference of a mixture of structured (e.g., panel discussion led by senior professors), semistructured (e.g., group discussions over a topic of choice), and unstructured interactions (e.g., happy hour networking). Overall the FLCs hold great promise for socializing, retaining, and promoting faculty without the feeling of standardized "workshops" or other training sessions. Having more conversational sessions can help new faculty explore career and personal life issues in a more natural context.

Given our findings of proactive personality, we suggest making faculty aware of their own proactivity tendencies during faculty orientations including NFLCs would be helpful. The assessment process does not take much time and has solid reliability and validity. However we would caution that this proactive scale would be best used as indicators of behaviors that faculty could do and of mindsets for planning research, teaching, and engagement. Faculty with lower scores can be more strategic in developing more proactive mindsets and take the initiative to engage in actions that can facilitate their career success. FLCs can be an ideal arena for faculty to learn about setting a proactive mindset and garnering proactive career strategies For example, examining the scale items (e.g., "Wherever I have been, I have been a powerful force for constructive change"; "If I see something I don't like, I fix"; "No matter what the odds, in I believe in something I will make it happen"; "I love being a champion for my ideas, even against other's opposition"; "I am always looking for better ways to do things"; see Bateman \& Crant, 1993, p113) during faculty discussions might prompt questions and discussions, including sharing of experiences in doing some of the behaviors indicated and the consequences of these behaviors.

Another suggestion from our participants regarding the development of NFLCs is about membership. Currently, the NFLC program that we examined is geared towards first-year tenuretrack faculty members. However, faculty expressed continued need for learning as they move along in their career; while the majority of the programming offered focused on the first year transitions into the faculty role, several faculty members noted that many of the lessons and conversations with senior faculty became important and made sense in their second year and 
onward. For instance, associate professors could relish the opportunity to attain sustained commitment to their careers and chance to network with new purposes.

\section{Limitations and Future Research}

Our findings are limited by the relatively small sample size and that we examined a NFLC program of a particular institution. The sample size for the survey data showed no significant difference between participants and non-participants; however, ideally, FLC programming would contribute to performance and various components of socialization. The paper offers a starting point to understand FLC programming from faculty participants' perspectives and develop a preliminary theoretical framework in understanding the effects of FLCs community in engineering. Future research can use cross-sectional and longitudinal data to generate fruitful insights of faculty learning community and its impact on faculty success, wellbeing, and institutional development and inclusivity. Another fruitful research project is to look at proactive personality and communication competence measures since different message design logics (Fairhurst, 2003) or communication styles might link in different ways to engage in proactive behaviors. Moreover, we call for additional studies to consider community engagement with communities of practice in university settings. Studies should particularly focus on how such "internal" community development efforts can help with the broader efforts of community engagement in engineering education.

\section{References}

Addis, E. A., Quardokus, K. M., Bassham, D. C., Becraft, P. W., Boury, N., Coffman, C. R., Colbert, J. T., \& Powell-Coffman, J. A. (2013). Implementing pedagogical change in introductory biology courses through the use of faculty learning communities. Journal of College Science Teaching, 43, 22-29. Retrieved from http://search.proquest.com/openview/053b7a7f54e14d4bca3267339d98bb35/1?pqorigsite $=$ gscholar

Anderson, C. M., Riddle, B. L. \& Martin, M. M. (1999). Socialization processes in groups. In L. R. Frey, D. S. Gouran \& M. S. Poole (eds), The handbook of group communication: Theory and research (pp. 139-163). Thousand Oaks, CA: Sage.

Ashforth, B. E., Mael, F. (1989). Social identity theory and the organization. The Academy of 296 Management Review, 14, 20-39. doi: 10.5465/AMR.1989.4278999

Bateman, T.S. \& Crant, J.M. (1993). The proactive component of organizational behavior: A measure and correlates. Journal of Organizational Behavior, 14, 103-118. doi: 10.1002/job.4030140202

Baumeister, R.F., \& Vohs, K.D. (2002). The pursuit of meaningfulness in life. In C.R. Snyder \& S.J. Lopez (Eds), Handbook of positive psychology (pp. 608-618). New York, NY: Oxford University Press.

Cheney, G., Christenson, L. T., \& Dailey, S. L. (2014). Communicating identity and identification in and around organizations. In Putnam, L. L., \& Mumby, D. K (Eds.), The 
SAGE handbook of organizational communication: advances in theory, research, and methods (pp. 695-716). Thousand Oaks, CA: SAGE publications.

Cox, M.D. (2004). Introduction to faculty learning communities. New Directions for Teaching and Learning, 97, 15-23. doi:0.1002/tl.129

Cox, M. D. (2003). Fostering the scholarship of teaching through faculty learning communities. Journal on Excellence in College Teaching, 14, 161-198. Retrieved from: http://www.mtsu.edu/ltanditc/docs/facultylearningcommun08.pdf

Cox, M.D. (1999). Peer consultation and faculty learning communities. New Directions for Teaching and Learning, 79, 39-49. doi: 10.1002/t1.7905

Crant, J. M. (1995). The proactive personality scale and objective job performance among real estate agents. Journal of Applied Psychology, 80, 532-537. doi:10.1037/00219010.80.4.532

Creswell, J.W., \& Plano Clark, V.L. (2007). Designing and conducting mixed methods research. Thousand Oaks, CA: Sage.

Ellemers, N., De Gilder, D., \& Haslam, S. A. (2004). Motivating individuals and groups at work: a social identity perspective on leadership and group performance. The Academy of Management Review, 29, 459-478. doi: 10.5465/AMR.2004.13670967

Flaherty, C. (2015, June 5). Losing hope in Wisconsin. Inside Higher Ed. Retrieved from https://www.insidehighered.com/news/2015/06/05/faculty-members-protest-tenure- sharedgovernance-changes-board-regents

Gabelnick, F., MacGregor, J., Matthews, R. S., \& Smith, B. L. (1990). Learning community foundations. New Directions for Teaching and Learning, 41, 5-18. doi: 10.1002/t1.37219904103

Glowacki-dudka, M., Brown, M. P. (2007). Professional development through faculty learning communities. New Horizons in Adult Education and Human Resource Development, 21, 29-39. doi: 10.1002/nha3.10277

Greene, J.C., Caracelli, V.J., \& Graham, W.F. (1989). Toward a conceptual framewrok for mixed-method evaluation designs. Education Evaluation and Policy Analysis, 11, 255-274. Article Stable URL: http://www.jstor.org/stable/1163620

Handley, K., Sturdy, A., Fincham, R., \& Clark, T. (2006). Within and beyond communities of practice: Making sense of learning through participation, identity and practice*. Journal of Management Studies. 43(3): 641-653.

Hogg, M. A., \& Terry, D. J. (2000). Social identity and self-categorization processes in organizational contexts. The Academy of Management Review, 25, 121-141.doi: 10.5465/AMR.2000.2791606 
Hubball, H., \& Albon, S. (2007). Faculty learning communities: Enhancing the scholarship of teaching, learning, and curriculum practice. Journal on Excellence in College Teaching, 18, 119-141. Article URL: http://celt.muohio.edu/ject/issue.php?v=18\&n=2

Ilies, R., Curşeu, P. L., Dimotakis, N., \& Spitzmuller, M. (2013). Leaders' emotional expressiveness and their behavioural and relational authenticity: Effects on followers. European Journal of Work and Organizational Psychology, 22, 4-14. doi: 10.1080/1359432X.2011.626199.

Jablin, F. M., \& Krone, K. J. (1987). Organizational assimilation: In C. R. Berger \& S. H. Chaffee (eds.), Handbook of communication science (pp. 711-746). Newbury Park, CA: Sage.

Kramer, M. W., \& Miller, V. (2014). Socialization and assimilation: Theories, processes, and outcomes. In Putnam, L. L., \& Mumby, D. K (Eds.), The SAGE handbook of organizational communication: advances in theory, research, and methods (pp. 525-547). Thousand Oaks, CA: SAGE publications.

Lankau, M. J., \& Scandura, T. A. (2007). Mentoring as a forum for personal learning in organizations. In B. R. Ragins, \& K. E. Kram (Eds.), The handbook of mentoring at work: Theory, research, and practice (pp. 95-122). Thousand Oaks, CA: SAGE publications.

Li, N., Liang, J., \& Crant, J. M. (2010). The role of proactive personality in job satisfaction and organizational citizenship behavior: a relational perspective. Journal of applied psychology, 95, 395. doi: $10.1037 / \mathrm{a} 0018079$

Li, W.D., Fay, D., Frese, M., Harms, P. D., \& Gao, X.Y. (2014). Reciprocal relationship between proactive personality and work characteristics: A latent change score approach. Journal of Applied Psychology, 99, 948. doi: 10.1037/a0036169

Long, Z., Buzzanell, P. M., Anderson, L. B., Batra. J. C., Kokini, K., \& Wilson, R.F. (2014). Episodic, network, and intersectional mentoring: Taking a communicative stance on mentoring in the workplace. In E. Cohen (Ed.), Communication Yearbook 38 (pp. 390414). New York, NY: Routledge.

Mael, F., \& Ashforth, B. E. (1992). Alumni and their alma mater: A partial test of the reformulated model of organizational identification. Journal of Organizational Behavior, 13, 103-123. doi:10.1002/job.4030130202

Myers, K. K., \& Oetzel, J. (2003). Exploring the dimensions of organizational assimilation: Creating and validating a communication measure. Communication Quarterly, 51, 436455. doi:10.1080/01463370309370166

Postmes, T., Tanis, M., \& De Wit, B. (2001). Communication and commitment in organizations: A social identity approach. Group Processes \& Intergroup Relations, 4, 227-246.

Smith, T. R., Mcgowan, J., Allen, A. R., Johnson. W .D., Dickson, L. A., Naje-ullah, M. A., Peters, M. (2008). Evaluating the impact of a faculty learning community on STEM teaching and learning. Journal of Negro Education, 77(3), 203-226. 
Shepherd, D.A., Patzelt, H., \& Haynie, J. M. (2009) Entrepreneurial spirals: Deviationamplifying loops of an entrepreneurial mindset and organizational culture.

Entrepreneurship Theory and Practice, 34, 59-82. doi:10.1111/j.1540-6520.2009.00313.x

Thompson, J. A. (2005). Proactive personality and job performance: A social capital perspective. Journal of Applied Psychology, 90, 1011-1017. doi: 0.1037/0021-9010.90.5.1011

Tönnies, F. (2002). Communities and Society. (C. Loomis, Ed.) Mineola, NY: Dover Publications, Inc.

Tovar, M., Jukier, R., Ferris, J., \& Cardoso K. (2015). Overcoming pedagogical solitude: The transformative power of discipline-specific faculty learning communities. To Improve the Academy, 34, 319-344. doi: 10.1002/tia2.20026

Wenger, E., McDermott, R. and Snyder, W. M. (2002). Cultivating Communities of Practice. Boston, MA: Harvard Business School Press

Whiteoak, J. W. (2014). The dynamic relationship among group efficacy perceptions, attributions and task performance. E - Journal of Social \& Behavioural Research in Business, 5(2). Retrieved from http://www.ejsbrb.org/upload/eJSBRB_Whiteoak_5(2)_2014.pdf 